\title{
An Overview of Three Dimensional (3D) Technologies in Forensic Odontology
}

\author{
Gargi Jani', Wenona Star Lavin², Suresh Ludhwani ${ }^{3}$ and Abraham Johnson ${ }^{4 *}$ \\ 'Laboratory of Forensic Odontology, School of Forensic Science, National Forensic Sciences University, \\ Gandhinagar - 382007, Gujarat, India; jani.gargi@yahoo.com \\ ${ }^{2}$ Forensic Radiographer, Defense POW/MIA Accounting Agency, Joint Base Pearl \\ Harbor-Hickam, Hawaii, US; starlavin@gmail.com \\ ${ }^{3}$ Department of Oral Medicine and Radiology, Karnavati School of Dentistry, Gandhinagar - 382422, \\ Gujarat, India; docsuresh.omr@gmail.com \\ ${ }^{4}$ Laboratory of Forensic Odontology, School of Forensic Science, National Forensic Sciences University, \\ Gandhinagar - 382007, Gujarat, India; drabrahamjohnson4000@yahoo.com
}

\begin{abstract}
Three-dimensional (3D) modalities are frequently applied in forensic practice as it tends to give complete information of the evidence merely by touching which has resulted in increased usage in legal medicine and forensic sciences. A number of sub-disciplines of forensic science utilises 3D modalities in an inter-disciplinary manner viz. forensic anthropology, forensic archaeology, forensic odontology, crime-scene investigation, pattern analysis and recovery, courtroom visualisation and ballistic comparison. With appropriate knowledge and utilisation of 3D scanning, modelling and printing technologies, innovative approaches can be implemented for identification in forensic cases. Given that these technologies are evolving rapidly and changing the face of forensic science, the present article collates current developments, working and applications of non-contact scanning techniques, modeling and 3D printing techniques.
\end{abstract}

Keywords: Digital Reproduction, Forensic Anthropology, Forensic Odontology, 3D Modeling, 3D Printing, 3D Scanning Article chronicle: Date of Submission: 22.3.2019; Date of Acceptance: 29.10.2019; Date of Publication: 24.04.2020

\section{Introduction}

Recent advances in the capabilities and accessibility of three-dimensional (3D) technologies have seen an increasingly widespread adoption of the systems as a tool for the investigation of crime and for establishing identification. In the present times, the use of three dimensional modalities should not be overlooked for investigative or court purposes, which is still comparatively new. Innovative approaches using 3D modalities assume a necessary part for the evolution in the various fields of forensics ${ }^{1}$. Since last few decades, the various forensic and medico-legal experts have gradually become acquainted with 3D modalities including 3D acquisition, 3D modeling and processing and 3D printing techniques ${ }^{2-4}$. It has been repeatedly demonstrated that virtual methods facilitate preservation, restoration, storage and conservation of evidence ${ }^{2,5}$. The 3D approach has evolved into a legitimate, recognized and stand alone methods for examining human skeletal remains, after the conversion of scanned data to digital models for editing, analysis and visualisation ${ }^{3,6,7}$.

3D modalities are frequently applied in forensic practice as it tends to give complete information of the evidence merely by touching which has resulted its increased usage in legal medicine and forensic sciences ${ }^{8,9}$. With commencement of such technologies, the 3D data acquisition is a fast-developing area in scientific research development and innovation. Its main applications in the field of forensics can be broadly categorized into: 1 . Spatial visualization and site-space analysis (as in case of crime scene investigation) and 2. Visualization and quantitative 
analysis. The end product provides a 3D model that may be scaled, rotated and examined from multiple viewpoints in $3 \mathrm{D}$ space, and further analysed, from internal and external aspects ${ }^{10}$.

The present literature aims to highlight the importance of 3D modalities, their functioning as well as their possible utilisation especially in the fields of forensic odontology and forensic anthropology. It can be utilized to its fullest potential when 3D scanners, processing/ remodelling software and various $3 \mathrm{D}$ printing techniques are amalgamated for best practices in forensics.

\section{Three-dimensional (3D) Imaging}

It refers to the process of data acquisition in $\mathrm{x}, \mathrm{y}$ and $\mathrm{z}$ coordinates that would represent an object in $3 \mathrm{D}$ space ${ }^{11}$. Two primary forms of $3 \mathrm{D}$ data acquisition devices exists: Volumetric scanners/transmissive and surface scanners/reflective ${ }^{12}$ (Figure 1) shows different three dimensional imaging techniques. External and internal structural geometry of entire object is obtained using volumetric scanners whereas surface scanners deal with the acquisition of the external surfaces of an object being scanned.

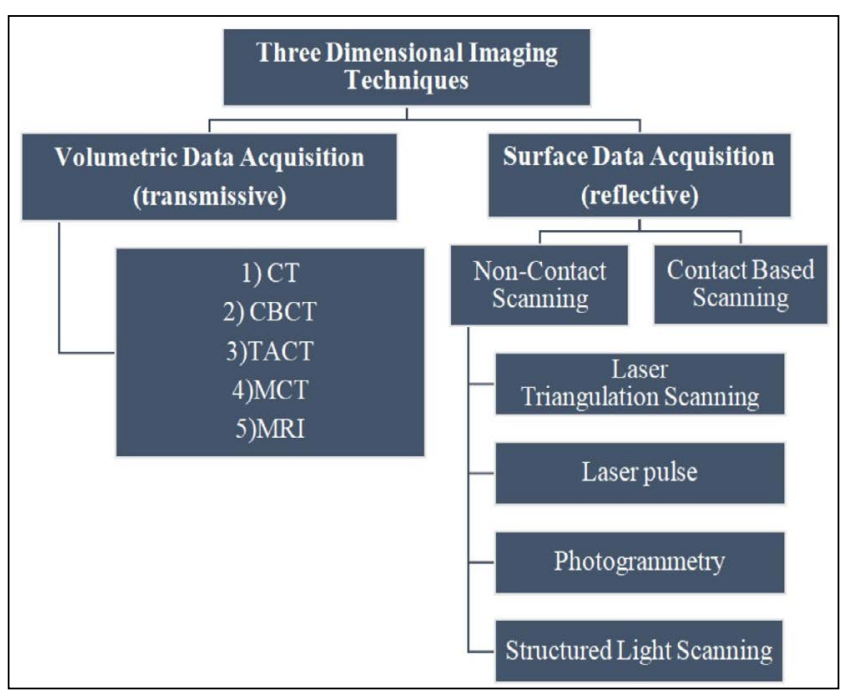

Figure 1: Classification of Three-Dimensional Imaging Modalities.

\section{Volumetric Data Acquisition}

For accurate acquisition of internal and external structures, methods based on the focused transmission of X-radiation have been utilised. The volumetric scanners utilised in forensics are Computed Tomography (CT), Cone Beam Computerized Tomography (CBCT), Micro-computed tomography (MCT), Tuned-aperture Computer Tomography (TACT) and Magnetic Resonance Imaging (MRI) ${ }^{13}$. Transmissive imaging techniques are based on passing the radiation through a sample to capture volumetric data. The advantage of this technique is that forensic evidence/human cadavers can be scanned even when they are packaged, or in cases where cadavers are macerated ${ }^{12}$. Visualisation of internal features of the human body becomes possible using this though quality may differ ${ }^{12}$. The individual image slices obtained are utilized to produce a virtual three-dimensional model, through a process known as $3 \mathrm{D}$ reconstruction. The volumetric data production involves discrete stages in which computer algorithms processes the geometry of an image stack through transformation, perspective creation, clipping, and lighting. Finally creating an image based on rastering (dot matrix data structure that represents a generally rectangular grid of pixels), shading, texturing and anti-aliasing ${ }^{10,14}$. Two models of images may be produced from this -

- Surface-rendered model represents points that have equal values of grey density which are then extracted and generalized as a series of polygons into a proper geometric surface ${ }^{10}$.

- Volume rendered model represents grey values as being partially opaque, allowing the observer to see into or through a solid structure to a greater or lesser extent $^{10}$.

\section{Surface Data Acquisition}

The Three Dimensional Surface Scanning (3DSS) devices utilizes acquisition of the outer structure and its accurate surface details, thus also known as reflective technique as it works by reflecting a light source onto a subject and recording the reflected data ${ }^{12}$. The 3 DSS scanners fall under two broad categories: contact scanners and noncontact scanners.

\section{Contact Scanning}

Contact 3D scanners probe objects through physical touch, while the object is placed on a flat surface ${ }^{15}$ (Figure 2). The probe contacts the object at various points resulting in acquisition of data. Accuracy of this method of data collection is more for geometrical objects rather 
than organic freeform shapes. However, the application of contact-based digitization is limited to the industrial needs. Due to the physical contact of object with the probe, it may modify or permanently damage the object making it of destructive type; which invalidates its use in forensics ${ }^{11,16}$.

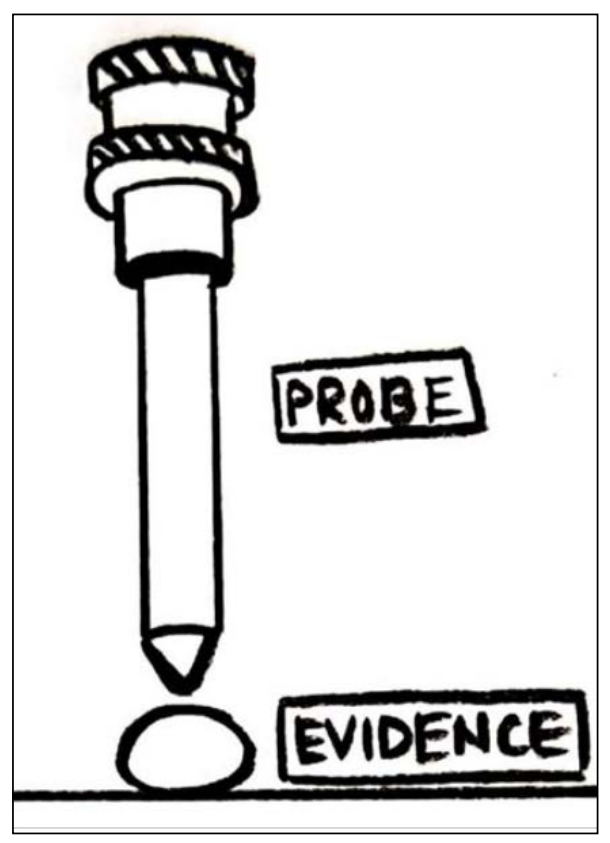

Figure 2: Contact based 3D scanning.

\section{Non-Contact Scanning}

Non-contact scanners are faster and simpler for data acquisition. The non-contact 3D scanners are of nondestructive type as there is no direct contact between the scanner and the object. They are further divided into active and passive subtypes. The active scanners reflect the light off an object's surface through an array of lenses and then onto an image sensor whereas the passive scanners illuminate objects using an undirected light source. ${ }^{11}$ The various non-contact scanning technologies are listed.

- Laser triangulation 3D scanners use a single laser point to scan across an object; where the laser beam projected by the scanner is reflected off from the object and is later received by the receptor ${ }^{17}$ (Figure 3). This laser trajectory, trigonometric triangulation and deviation angle is perceived by the system. Here, the calculated angle is directly proportional to the distance from the object to the scanner. It generates the point cloud data from the collected information, after which the mesh is created. These meshes can be cleaned and stitched together to form a complete 3D model of the entire surface. The triangulation method is more appropriate for recording smaller objects. ${ }^{11,18,19}$ The advantage is its resolution and accuracy. However the shiny and transparent surfaces are difficult to be recorded with this type of scanners. Thus, useful in archaeological department for data collection and analysis ${ }^{11}$.

- Structured light 3D scanners use trigonometric triangulation principle and rely on the structured light (white or blue light) which projects a series of linear patterns on an object (Figure 4). The system examines the edges of each line in the pattern and calculates the distance from the scanner to the object's surface ${ }^{11}$. Light modulators produce pattern of lights based on different technologies, where the displacement of individual stripe is converted to $3 \mathrm{D}$ coordinate of the object. Structured light scanning has the ability to capture geometric, morphometric and colour surface data. The advantage is its speed, resolution and ability to scan large objects ${ }^{11,19}$. Thus, it is majorly used in the area of forensic sciences as well as in face identification.

- Photogrammetry reveals the geometric properties of the object to be scanned through various photographic images. The principle of photogrammetry is to take multiple images of the object from various positions with common reference point in each image which eliminates modelling of an object and also captures the original color of the object used (Figure 5). A photogrammetry software is used to process and develop a $3 \mathrm{D}$ model of the object from the photographs. Due to its precision and acquisition speed, photogrammetry is also capable of reconstructing objects of various scales. The disadvantages of this technology are its sensitivity to the resolution of the input photographs and the time it takes to run the algorithms. However, it is widely used in documentation of taphonomic changes, archaeological department and crime scene management ${ }^{11,20}$.

- Laser Pulse Based Scanners also known as lidar or time of flight scanners are based on the time taken by laser to hit target and return. The distance can be easily calculated as the speed of light is defined. It has higher resolution compared to other non-contact 
scanners. The scanner needs to be moved across the scene to ensure the laser scan captures previously unseen surfaces when applied to larger area. The individual scans are manually stitched together to create a full representation of the whole scene; thus it is useful in crime scene documentation ${ }^{11,21}$.

Various studies have been conducted till date to determine the quality of digitized 3D models in terms of repeatability, reproducibility and robustness of the digitalization process. The literature supports 3DSS, CT and CBCT scanners, along with optical and laser scanning as commonly employed technologies for forensic purpose ${ }^{9,22}$. The use of micro-CT gives higher image resolution with the voxel size less than $0.001 \mathrm{~mm}$ but its application is less in practice due to its high $\cos ^{23}$. Moreover, the literature states that expertise is required to operate volumetric scanners which are quite expensive, thus decreasing its popularity over surface scanners ${ }^{24,25}$. Also, the volumetric scanners other than micro-CT gives lower accuracy and external surface details when compared to surface scanners which in turn give higher resolution, surface texture and colored $\mathrm{data}^{26,27}$. The volumetric data obtained has complex internal geometry of an object and when working with complex anatomical structures it results in large files which in turn hamper the computer performance. Also surface scanners does not emit harmful radiations as in case of volumetric scanners $^{28,29}$.

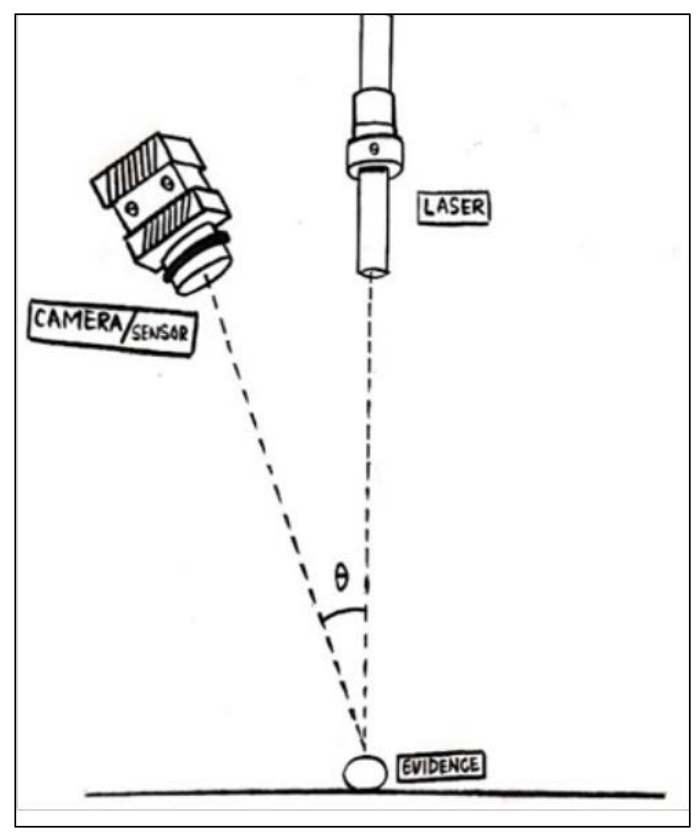

Figure 3: Laser triangulation technique.

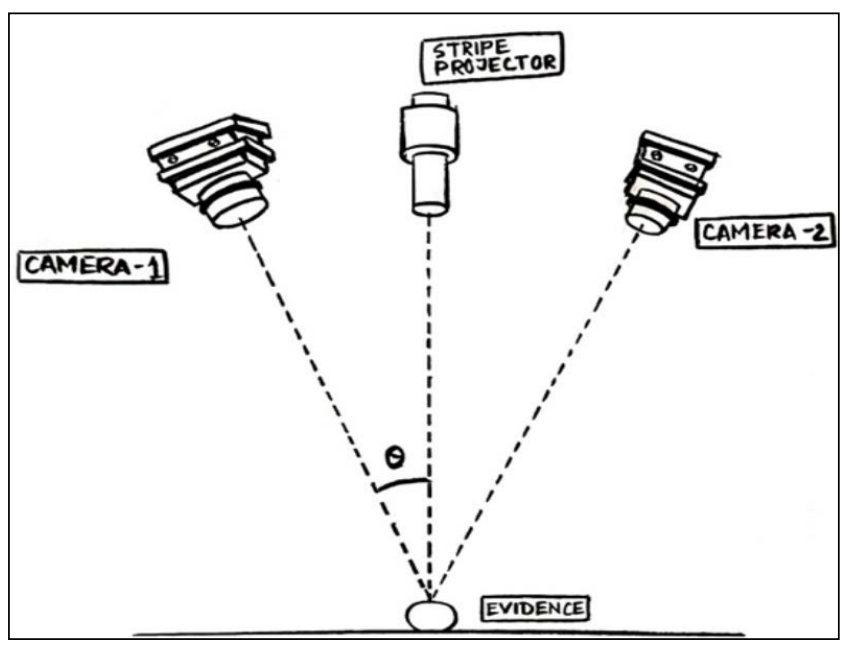

Figure 4: Structured light 3D scanning technology.

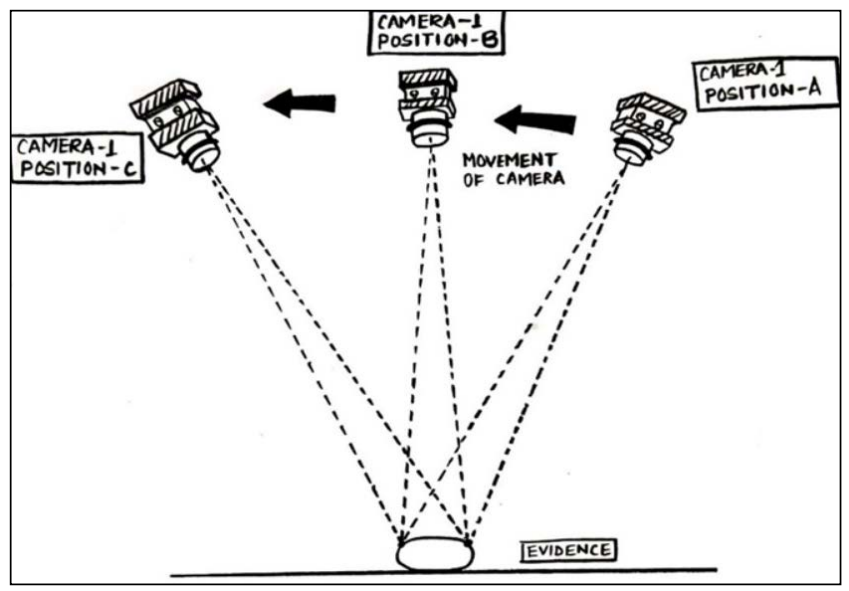

Figure 5: Photogrammetry.

\section{Three-dimensional (3D) Modeling}

Three-dimensional (3D) modeling of an object can be referred to the process of converting a measured point cloud into a triangulated network ('mesh') or textured surface where as rendering is a algorithm which transforms the model and creates a 3D data in display coordinates. Rendering converts the object properties into pixel values ${ }^{30}$.

\section{For Volumetric Data}

Volumetric data are based on image slices from Computed Tomographic (CT) scanners and/or cone Beam Computed Tomography Scanners (CBCT). The individual image slices from a CT/CBCT are used to produce a virtual three-dimensional object, through a process known as $3 \mathrm{D}$ reconstruction ${ }^{10}$. The most 
important aspect of this process is rendering to the image volume. Rendering involves discrete stages by which computer algorithms process the geometry of an image stack, through transformation, perspective creation, clipping, and lighting, and in doing so create an image based on rastering, shading, texturing and anti-aliasing ${ }^{10}$. From this rendering process, two modes of images may be produced - a surface-rendered model or a volumerendered model (Figure 6).

- Surface-rendered model (or isosurface) represents points that have equal values of grey density which are then extracted and extrapolated as a series of polygons into a proper geometric surface.

- Volume rendering on the other hand, treats grey values as being partially opaque, allowing the observer to see into or through a solid structure to a greater or lesser extent.

In practice iso-surface rendering is the preferred option for subsequent interrogation of surfaces, and iso-surface files can be exported as relatively small digital models in common formats such as PLY or STL for subsequent manipulation and landmarking using proprietary or open-source software ${ }^{10}$.

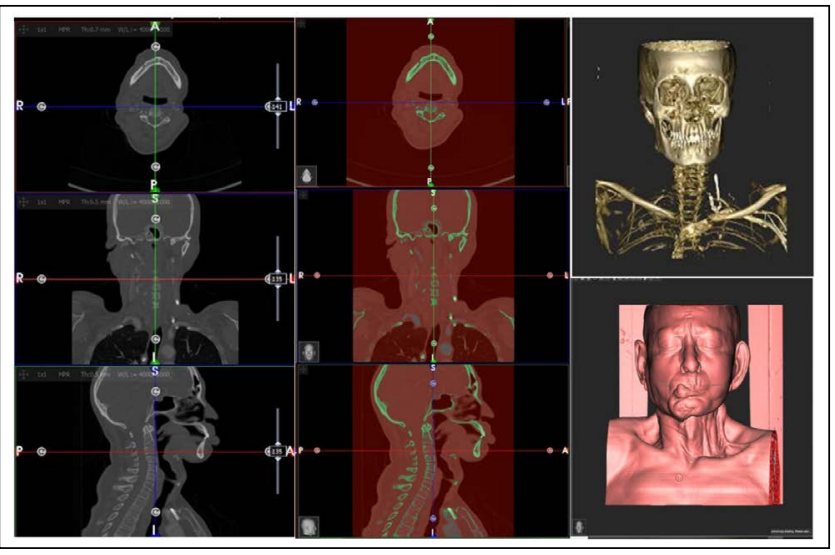

Figure 6: Volumetric Data acquisition and processing.

\section{For Surface Scanned Data}

The data acquisition starts with the recording of surface geometry (shape), texture (colour or detail) or both. Point cloud of varying densities is generated from the raw data. (Figure 7) Point cloud is a set of points that is depicted the position (X, $\mathrm{Y}$, and $\mathrm{Z}$ ), intensity (I), and colour (R, G, and B) value data for scanned objects. ${ }^{11}$

Post processing of raw data comprises of:
- Cleaning ${ }^{31}$ : Initially a noise clean-up is done to remove the background noise from the raw data (Figure 7A).

- Reconstruction ${ }^{31}$ : After noise clean up the individual data are aligned to create a single model. This is done using auto alignment/global registration which is based on Iterative Closest Point (ICP) algorithm which relies on minimizing the difference between two clouds of points, thus aligning the geometry of two objects. In case of complex structure, the points on the raw data are aligned manually by selecting points on three basis vectors ( $\mathrm{x}, \mathrm{y}$ and $\mathrm{z}$ ). After aligning and creating a complete object, base removal is done Figure 7 (B and C).

- Fusion of raw data ${ }^{31}$ : Once the object geometry is complete, the points or vertices are rendered into mesh, which is generally comprised of algorithmically interconnected polygonal plane that represents surface. On this mesh, a rendered surface is applied, where the recorded points in a cloud are connected together into a continuous 3D surface approximation. The final model is down-sampled, smoothened, and decimated (i.e. the number of triangles is reduced) in order to remove extraneous features. This makes the file size small enough to be used in a variety of software packages ${ }^{10}$ (Figure 7D, E and F).

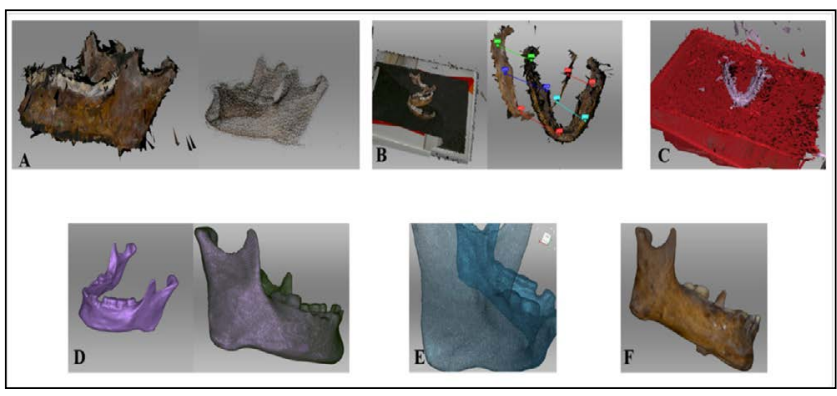

Figure 7: Processing for Surface scanned data (A) Noise Clean up (B)Alignment of individual scans (C)Removal of base (D) Fusion of raw data (E) Mesh of the model (F) Final surface rendered model.

\section{Three-dimensional (3D) Printing}

$3 \mathrm{D}$ printing is a powerful tool that allows for a model of evidence to be created, thus an aid to develop teaching collections in teaching laboratory and for hands-on museum exhibits for educating the public. Having a prototype model of the original specimen also helps to prevent over handling of the original, and a mould can be made from the replica, with further copies produced at a lower $\cos ^{26}$. 3D printing is alias with additive 
manufacturing ${ }^{32}$. To create a physical3D model, Computer Assisted Design (CAD) software is essential as it allows to form the basic design in virtual environment ${ }^{32}$ (Figure 8). The precision of the 3D printed model depends on the technology such as Fused Deposition Modelling (FDM), Stereolithography (SLA), Digital Light Processing (DLP), Photopolymer Jetting (PPJ), Powder Binder Printers (PBP), Selective Laser Sintering (SLS) etc. ${ }^{32}$. Figure 8 describes the general workflow for the printing process.

- Fused Deposition Modelling (FDM) is one of the earliest technologies where FDM printers have robotic extruders which traverses on the stationary platform or has a stationary extruder and a movable platform ${ }^{33}$. The digital model created are sliced into the layer and support structures are added in the software and then the co-ordinates are transferred to the printers ${ }^{33,34}$. The most important material selection criteria for FDM materials are heat transfer characteristics (thermoplastic) and rheology ${ }^{34}$. A commonly used material is the biodegradable Polymer Polylactic Acid (PLA); or similar materials such as Polyvinyl Chloride (PVC), nylon, Acrylonitrile Butadiene Styrene (ABS) and investment casting wax have been used as key components of scaffold structures ${ }^{34}$. The models prepared using this material have high porosity, variable mechanical strength, lower accuracy when compared to other materials, limited shape complexity ${ }^{33,35}$.

- Stereolithography (SLA) uses a scanning laser to build parts one layer at a time, in a vat of light-cured photopolymer resin where light sensitive polymer is cured layer by layer ${ }^{33,36}$. Each layer is traced-out by the laser on the surface of the liquid resin, at which point a 'build platform' descends and another layer of resin is wiped over the surface. The process is repeated till the object is created. Supports are created in the CAD software and printed to resist the wiping action and to resist gravity, which are removed from the finished product. Post-processing involves removal of excess resin and a hardening process in a UV oven ${ }^{43}$. The advantage of this technology is rapid fabrication and ability to create complex shapes with high feature resolution though it has limited shelf life ${ }^{33}$.

- Digital Light Processing (DLP) uses a projector light source for curing the liquid resin layer by layer. Here, the object is constructed on an elevating platform in upside down manner. The polymer is layered pending the object is constructed, and the residual liquid polymer is drained off ${ }^{37,38}$. The advantage of this technology is good accuracy, the created surfaces are smooth, relatively fast and of lower $\cos ^{33}$.

- Selective Laser Sintering (SLS) uses scanning laser that fuses a fine material powder, to build up structures layer by layer, as a powder bed drops down incrementally, and a new fine layer of material is evenly spread over the surface ${ }^{39,40}$. This is also Selective Laser Melting (SLM) or Direct Metal Laser Sintering $(\mathrm{DMLS})^{33}$. A high $(60 \mu \mathrm{m})$ level of resolution may be obtained and as the structures that are printed are supported by the surrounding powder, no support material is required ${ }^{41,42}$. The technology is costly to purchase, maintain and run, therefore requiring copious quantities of compressed air. The materials are intrinsically dusty, have some health and safety requirements and are rather messy to work with ${ }^{33}$. Materials available include nylon, which is perhaps the most versatile, flexible elastomeric materials and metal-containing nylon mixtures ${ }^{33}$.

- Photopolymer Jetting (PPJ) uses light cured resin materials and print heads rather like those found in an inkjet printer (but considerably more costly), to lay down layers of photopolymer which are light cured with each pass of the print head ${ }^{33}$. A variety of materials may be printed including resins and waxes for casting, as well as some silicone-like rubber materials. Complex geometry and very fine detail is possible - as little as 16 microns resolution ${ }^{44}$.

- Powder Binder Printers (PBP) uses a modified inkjet head to print using, what is essentially, liquid droplets to infiltrate a layer of powder, layer by layer. Typically a pigmented liquid, which is mostly water, is used to print onto the powder, which is mostly plaster of paris $^{33,44}$. The accuracy obtained is less also lower strength is obtained ${ }^{44}$.

\section{Potential Application in Forensic Odontology and Anthropology}

- Documentation - It is one of the basic applications of 3D imaging (Figure 9A) where the scanned data can be saved and archived for future reference. Archiving data ensures that the actual state of the remains can be documented and re-examined in case the original evidence is altered. The external injuries documented 
can later help in investigation of the weapon and time since the injury was inflicted ${ }^{45}$. The human remains as well as bones can be documented to study taphonomic changes and alterations. Moreover, the 3D data can also be digitally transferred to other forensic experts, allowing them to consult on cases without having to transport the remains ${ }^{46}$.

- Analytical Procedures - When the original anthropological and dental remains are unavailable or cannot be handled physically, the 3D digitized data can be used for point-to-point measurement (Figure 9C). Volumetric measurements such as surface area, volume and surface-curvatures can also be done using the scanned data. The literature ascertains the precise measurements obtained using scanned data and can aid in determination of age and sex; thus aid in developing accurate biological profiles ${ }^{29,46}$. Volumetric imaging of living and dead can also aid in sexual dimorphism by analysis of para-nasal sinuses thus offering a solution for age estimation of the living ${ }^{47}$. Pattern analysis such as fingerprints, foot prints can be done by using laser scanners ${ }^{48}$. The bitemark patterns as well as the dental casts can be digitized and thus used for further analysis and digital superimposition $^{49}$. 3D model analysis is one of the important analytical application for research purpose in cases of reconstruction ${ }^{50,51}$ (Figure 10).

- Virtual Reconstruction and Remodelling - Virtual reassembly of fragmented bones (Figure 9B) can be carried out to generate a single unit which can be printed as single assembly in contrast to the traditional practice of reassembling bone fragments using adhesive materials such as glue ${ }^{5}$. Virtual reconstruction
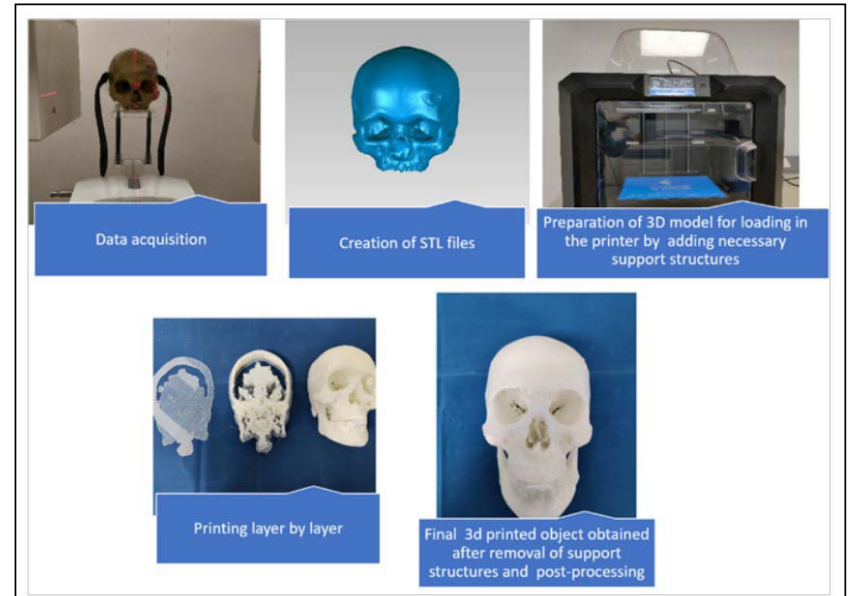

Figure 8: General work flow for 3D Printing.

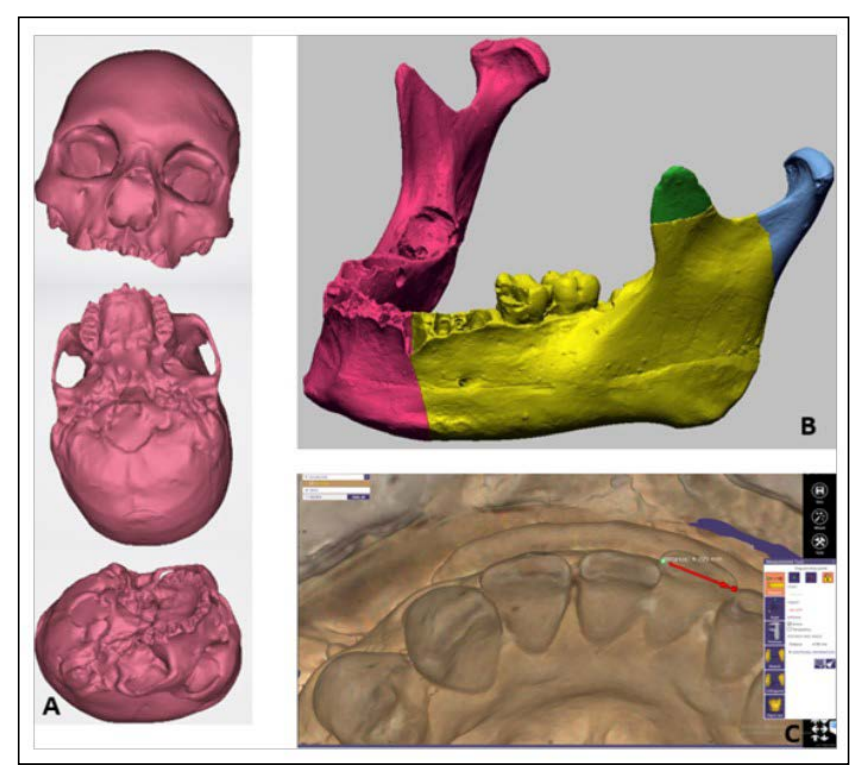

Figure 9: Applications of 3D Scanning: Documentation (A), Virtual Reconstruction (B), Metric analysis (C).

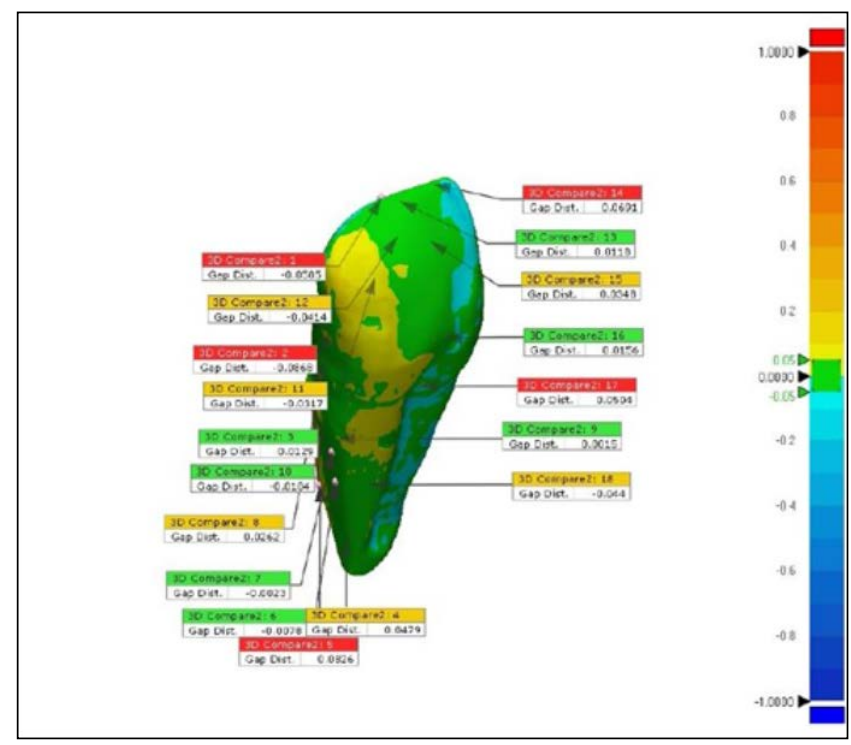

Figure 10: 3D superimposition for morphological analysis.

is advantageous as it allows the evidence to remain in its original condition ${ }^{25,26}$. Virtual reconstruction of missing elements has been reported by using geometric morphometrics which aid in positive identification ${ }^{48}$. A number of methodologies are used under the title of reconstructive forensics for virtual reconstruction which include mirroring, thin plate spline function, reverse engineering with geometric morphometrics, superimposition and incremental techniques, ${ }^{52-55}$. 
Authors have also demonstrated the use of 3D scanning and printing to reconstruct the post-mortem missing teeth from empty dental sockets ${ }^{50}$. At the end, a 3D model is generated either in .obj (Wavefront OBJect) and .stl (Standard Tessellation Language) format which can be analysed using number of software packages such as Freeform, Polyworks, Autodesk Maya Sensable Technologies, ITK-Snap, ZBrush etc.

- Forensic Facial Reconstruction - Automated facial approximation or utilization of $3 \mathrm{D}$ modelling and digital sculpting programs can be performed digitally by $3 \mathrm{D}$ modeling software. Facial approximation deals with generalized facial type which are deciphered from the basic skull characteristics. Acquisition volumetric data is another technique utilized in automated computerized facial approximations. The basic limitation of facial approximation system that Wilkinson ${ }^{56}$ describes is that there will always be some resemblance to original facial template used. Other than that, the method relies on tissue depth data, and validation studies for the same are yet to be done.

Unlike the automated systems, this method requires 3D modelling skills, anthropological and anatomical knowledge. A 3D model of the skull is also required, and can be easily obtained through the use of a laser-scanner ${ }^{57}$.

\section{Conclusion}

It can be concluded that the use of 3D modalities in forensics is a humanitarian approach as the evidence is not damaged during the handling and analytical procedures. With appropriate knowledge, the 3D scanning, modeling and printing can be used to bring innovative approaches in solving forensic cases. Routine collection of biological data using CT or laser scanning of skeletal structures will provide a permanent repository for information that can be used in absence of the skeletal collection or in case of fragile skeletal remains. Also a digital repository can be created for odontological and anthropological remains for creation of data base. The practice of scanning the remains would limit the commingling, loss, and damage to the physical specimens. The scanned and printed data can serve as evidence in court as well as allows to perform various analytic procedures by limiting repeated handling of evidence for forensic analysis. 3D technology can aid greatly in the field of forensics if appropriate protocols are developed and adapted.

\section{References}

1. Johnson A, Pandey A. Three-dimensional scanning - A futuristic technology in forensic anthropology. Journal of Indian Academy of Forensic Medicine. 2019;41(2):128-31. https://doi.org/10.5958/0974-0848.2019.00035.6

2. Jurda M, Urbanova P, Chmelík J. Digital restoration of fragmentary human skeletal remains: Testing the feasibility of virtual reality. J Forensic Leg Med. 2019;66:50-7. PMid: 31220789. https://doi.org/10.1016/j.jflm.2019.06.005

3. Vanezis P, Blowes RW, Linney AD, Tan AC, Richards R, Neave R. Application of 3-D computer graphics for facial reconstruction and comparison with sculpting techniques. Forensic Sci Int. 1989;42(1-2):69-84. https://doi. org/10.1016/0379-0738(89)90200-4

4. Rusinek H, Noz ME, Maguire GQ, et al. Quantitative and qualitative comparison of volumetric and surface rendering techniques. IEEE Trans Nucl Sci. 1991;38(2):659-62. https://doi.org/10.1109/23.289371

5. Jani G, Johnson A, Belcher W. Forensic Science International: Reports Case report: Digital restoration of fragmented non-human skull. Forensic Science International: Reports, January 2020. 100070. https://doi. org/10.1016/j.fsir.2020.100070

6. Norman DG, Watson DG, Burnett B, Fenne PM, Williams MA. The cutting edge micro-CT for quantitative toolmark analysis of sharp force trauma to bone. Forensic Sci Int. 2018;283:156-72. PMid: 29304390. https://doi. org/10.1016/j.forsciint.2017.12.039

7. Jurda M, Urbanova P. Sex and ancestry assessment of Brazilian crania using semiautomatic mesh processing tools. Leg Med. 2016;23:34-43. PMid: 27890100. https:// doi.org/10.1016/j.legalmed.2016.09.004

8. Grabherr S, Grimm J, Baumann P, et al. Application of contrast media in post-mortem imaging (CT and MRI). Radiol Med. 2015;120:824-34. PMid: 25841652. https://doi.org/10.1007/s11547-015-0532-2

9. Fahrni S, Campana L, Dominguez A, Uldin T, Delémont O, Grabherr S, et al. CT-scan vs. 3D surface scanning of a skull: First considerations regarding reproducibility issues. Forensic Sci Res [Internet]. 2017;2(2):93-9. PMid: 30483625 PMCid: PMC6197135. https://doi.org/10.1080/2 0961790.2017 .1334353

10. Randolph-Quinney PS, Haines SD, Kruger A. The use of three-dimensional scanning and surface capture methods in recording forensic taphonomic traces: Issues of Technology, Visualisation and Validation. Soil Forensics. 2018;115-30. 10.1007/978-3-319-94397-8_8

11. Farahani N, Braun A, Jutt D, Huffman T, Reder N, Liu Z, et al. Three dimensional Imaging and Scanning: Current and Future Applications for Pathology. 2019;1-10.

12. Carew RM, Errickson D. Imaging in forensic science: Five years on. Journal of Forensic Radiology and Imaging. 
16(December 2018). 2019;24-33. https://doi.org/10.1016/j. jofri.2019.01.002

13. Karatas $\mathrm{OH}$, Toy E. Three-dimensional imaging techniques: A literature review. Eur J Dent 2014;8:132-40. PMid: 24966761 PMCid: PMC4054026. https://doi. org/10.4103/1305-7456.126269

14. The Printing connection. 2019. https://www.printcnx. com/resources-and-support/addiational-resources/rasterimages-vs-vector-graphics/

15. Mitbauerova A, Capek L, Ogawa R. A method of scar evaluation using non-contact 3D scanner. Comput Methods Biomech Biomed Engin. 2013;16:302-4. PMid: 23923951. https://doi.org/10.1080/10255842.2013.815915

16. Karsten L. Coordinate measuring machine. CIRP Encyclopedia of Production Engineering. $2^{\text {nd }}$ ed. Berlin, Germany: Springer International Publishing AG; 2014.

17. Chougule VN, Gosavi HS, Dharwadkar MM, Gaind AA. Review of different 3D Scanners and Scanning Techniques. 2018;41-4.

18. Gupta R, Chaudhari H. A literature review on low cost 3D scanning using structure light and laser light scanning technology. International Journal of Innovative Research in Science, Engineering and Technology. 2017 Jul; 6(7).

19. Aniwaa. 2019. https://www.aniwaa.com/3d-scanning-technologies-and-the-3d-scanning-process/

20. Carlton CD, Mitchell S, Lewis P. Preliminary application of structure from Motion and GIS to document decomposition and taphonomic processes. Forensic Sci Int. 2018;282:41-5. PMid: 29149686. https://doi.org/10.1016/j. forsciint.2017.10.023

21. Newnham GJ, Armston JD, Calders K, Disney MI, Lovell J, Schaaf CB, Strahler AH, Danson FM. Terrestrial laser scanning for plot-scale forest measurement. Remote Sens. 2015;1:239-51. https://doi.org/10.1007/s40725-015-0025-5

22. Kamburoglu K, Kursun S, C. Kilic C, Ozen T. Accuracy of virtual models in the assessment of maxillary defects. Imaging p Science in Dentistry. 2015;45(1):23-9. PMid: 25793180 PMCid: PMC4362988. https://doi.org/10.5624/ isd.2015.45.1.23

23. Kulczyk T, Rychlik MB, N DL, B MA, Czajka-jakubowska A, N AP. Computed Tomography versus Optical Scanning : A comparison of different methods of 3D data acquisition for tooth replication. 2019;2019:9-11. PMid: 31093500 PMCid: PMC6481121. https://doi.org/10.1155/2019/4985121

24. Komar D, Davy-Jow S, Decker S. The use of a 3-D laser scanner to document ephemeral evidence at crime scenes and postmortem examinations. Journal of Forensic Science. 2012;57:188-91. PMid: 21939441. https://doi.org/10.1111/ j.1556-4029.2011.01915.x

25. Kuzminsky S, Gardiner M. Three-dimensional laser scanning: Potential uses for museum conservation and scientific research. Journal of Archaeological Science. 2012;39:274451. https://doi.org/10.1016/j.jas.2012.04.020
26. Fantini M, Crescenzio F, Persiani F, Benazzi S, Gruppioni G. 3D restitution, restoration and prototyping of a medieval damaged skull. Rapid Prototyping Journal. 2008;14:318-24. https://doi.org/10.1108/13552540810907992

27. Niven L, Steele TE, Finke H, Gernat T, Hublin J. Virtual skeletons: Using a structured light scanner to create a $3 \mathrm{D}$ faunal comparative collection. Journal of Archaeological Science. 2009;36:2018-23. https://doi.org/10.1016/j.jas.2009.05.021

28. Park HK, Chung JW, Kho HS. Use of hand-held laser scanning in the assessment of craniometry. Forensic Science International. 2006;160:200-6. PMid: 16289612. https://doi.org/10.1016/j.forsciint.2005.10.007

29. Sholts SB, Warmlander SKTS, Flores LM, Miller KWP, Walker PL. Variation in the measurement of cranial volume and surface area using 3D laser scanning technology. Journal of Forensic Sciences. 2010;55:871-6. PMid: 20384925. https://doi.org/10.1111/j.1556-4029.2010.01380.x

30. Badler NI, Glassner AS. 3D object modeling. 2000; 27:8.

31. Mohamed MA. Shamata. Non-contact 3D surface scanning of traumatic injuries for forensic medicine. 68-87.

32. Dawood A, Marti BM, Sauret-Jackson V, Darwood A. 3D printing in dentistry. British Dental Journal. 2015;219(11):521-9. PMid: 26657435. https://doi. org/10.1038/sj.bdj.2015.914

33. Torabi K, Farjood E, Hamedani S. Rapid prototyping technologies and their applications in prosthodontics, a review of literature. J Dent Shiraz Univ Med Sci. 2015;16:1-9.

34. Chia $\mathrm{HN}$, Wu BM. Recent advances in $3 \mathrm{D}$ printing of biomaterials. Journal of Biological Engineering. 2015;9(1):1-14. PMid: 25866560 PMCid: PMC4392469. https://doi.org/10.1186/s13036-015-0001-4

35. Melchels F, Feijen J, Grijpma DW. A review on stereolithography and its applications in biomedical engineering. Biomaterials. 2010;31:6121-30. PMid: 20478613. https://doi.org/10.1016/j.biomaterials.2010.04.050

36. EOS GmbH. Additive manufacturing: possibilities, benefits and functional principle. EOS e-Manufacturing Solutions. 2020 Feb. www.eos.info/additive_manufacturing/for_technology_interested

37. Masri R, Driscoll CF. Clinical applications of digital dental technology. London: Wiley; 2015. https://doi. org/10.1002/9781119045564

38. Nayar S, Bhuminathan S, Bhat WM. Rapid prototyping and stereolithography in dentistry. J Pharm Bioallied Sci. 2015;7:S216-9. PMid: 26015715 PMCid: PMC4439675. https://doi.org/10.4103/0975-7406.155913

39. Deckard C, Beaman J. Process and control issues in selective laser sintering. ASME Prod Eng Div PED. 1988;33:191-7.

40. Kruth JP, Vandenbroucke B, Van Vaerenbergh J, Mercelis P. Benchmarking of different SLS/SLM processes as rapid manufacturing techniques. Proceedings of $1^{\text {st }}$ Int Conf of Polymers and Moulds Innovations; Gent, 2005. 
41. Ono I, Abe K, Shiotani S, Hirayama Y. Producing a fullscale model from computed tomographic data with the rapid prototyping technique using the binder jet method: A comparison with the laser lithography method using a dry skull. J Craniofac Surg. 2000;11:527-37. PMid: 11314492. https://doi.org/10.1097/00001665-200011060-00004

42. Silva DN, Gerhardt de Oliveira M, Meurer E, Meurer MI, Lopes da Silva JV, Santa-Barbara A. Dimensional error in selective laser sintering and 3D-printing of models for craniomaxillary anatomy reconstruction. J Craniomaxillofac Surg. 2008;36:443-9. PMid: 18579391. https://doi. org/10.1016/j.jcms.2008.04.003

43. Ibrahim D, Broilo TL, Heitz C et al. Dimensional error of selective laser sintering, three-dimensional printing and PolyJet models in the reproduction of mandibular anatomy. J Craniomaxillofac Surg. 2009;37:167-73. PMid: 19056288. https://doi.org/10.1016/j.jcms.2008.10.008

44. Ciuffolo F, Epifania E, Duranti G et al. Rapid prototyping: A new method of preparing trays for indirect bonding. Am J Orthod Dentofacial Orthop. 2006;129:75-7. PMid: 16443482. https://doi.org/10.1016/j.ajodo.2005.10.005

45. Raneri D, Raneri D. Enhancing forensic investigation through the use of modern three-dimensional (3D) imaging technologies for crime scene reconstruction reconstruction. Aust J Forensic Sci [Internet]. 2018;0618:1-11. https://doi.org/10.1080/00450618.2018.1424245

46. Buck U, Bube K, Campana L, Schyma C. Validation and evaluation of measuring methods for the $3 \mathrm{D}$ documentation of external injuries in the field of forensic medicine. International Journal of Legal Medicine. 2017;132(2):551-61. PMid: 29260394. https://doi.org/10.1007/s00414-017-1756-6

47. Vera NPM, Holler J, Widek T, Neumayer B, Ehammer T, Urschler M. Forensic age estimation by morphometric analysis of the manubrium from 3D MR images, Forensic Sci Int. 2017;277:21-9. PMid: 28550762. https://doi. org/10.1016/j.forsciint.2017.05.005

48. Komar D, Davy-Jow S, Decker S. The use of a 3-D laser scanner to document ephemeral evidence at crime scenes and postmortem examinations. Journal of Forensic Science. 2012;57:188-91. PMid: 21939441. https://doi.org/10.1111/ j.1556-4029.2011.01915.x
49. Kurniawan A, Yodokawa K, Kosaka M, Ito K, Sasaki K, Aoki T, Suzuki T. Determining the effective number and surfaces of teeth for forensic dental identification through the $3 \mathrm{D}$ point cloud data analysis. Egyptian Journal of Forensic Sciences. 2020;10(1):3. https://doi.org/10.1186/ s41935-020-0181-z

50. Johnson A, Jani G, Pandey A, Patel N. Digital tooth reconstruction: An innovative approach in forensic odontology. J Forensic Odontostomatol. 2019 Dec;3(37):12-20.

51. Park ME, Shin SY. Three-dimensional comparative study on the accuracy and reproducibility of dental casts fabricated by $3 \mathrm{D}$ printers. Journal of Prosthetic Dentistry. 2018;119(5):861.e1-861.e7. PMid: 29475753. https://doi. org/10.1016/j.prosdent.2017.08.020

52. Benazzi S, Stansfield E, Kullmer O, Fiorenza L, Gruppioni G. Geometric morphometric methods for bone reconstruction: The Mandibular Condylar Process of Pico della Mirandola. 2009;1097(Dec2008):1088-97. PMid: 19645014. https://doi.org/10.1002/ar.20933

53. Guyomarc P, Velemi P, Alena S, Samsel M. Virtual reconstruction of the Upper ' $\mathrm{K}$ ůn , Czech Palaeolithic skull from Zlaty Republic: Sex assessment and morphological affinity ef č a. 2018; 1-29.

54. Pratique E. 3D morphometrics and missing data. Can extant taxa give clues for the analysis of fossil primates? Comptes Rendus Palevol 3D geometric morphometrics and missing-data. Can extant taxa give clues for the analysis of fossil primates? Morphométriegéométrique 3D et donnéesmanquantes. Les taxonsactuels. 2017. September 2010. https://doi.org/10.1016/j.crpv.2010.07.002

55. Thali MJ, Braun M, Dirnhofer R. Optical 3D surface digitizing in forensic medicine: $3 \mathrm{D}$ documentation of skin and bone injuries. Forensic Science International. 2003;137:203-8. PMid: 14609658. https://doi.org/10.1016/j. forsciint.2003.07.009

56 Wilkinson C. Computerized forensic facial reconstruction: A review of current systems. Forensic Science, Medicine and Pathology. 2005;1:173-8. https://doi.org/10.1385/ FSMP:1:3:173

57. Michael SD, Chen M. The 3-D reconstruction of facial features using volume distortion. Proceedings of 14th Annual Conference of Eurographics, UK. 1996. p. 297-305.
How to cite this article: Jani G, Lavin WS, Ludhwani $S$ and Johnson A. An Overview of Three Dimensional (3D) Technologies in Forensic Odontology. J Forensic Dent Sci 2020;12(1):56-65.

\begin{tabular}{|l|c|}
\hline \multicolumn{2}{|c|}{ Access this article online } \\
\hline \multirow{3}{*}{ Website: } & Quick Response Code \\
\cline { 2 - 2 } www.jfds.org & Q \\
& \\
\hline
\end{tabular}

